\title{
OS TRÊS MOMENTOS PEDAGÓGICOS E A INTERDISCIPLINARIDADE NO ENSINO DE CIÊNCIAS DA NATUREZA: ANÁLISE DE UM CURSO DE FORMAÇÃO CONTINUADA
}

\author{
THE THREE PEDAGOGICAL MOMENTS AND \\ INTERDISCIPLINARITY IN THE TEACHING OF NATURAL \\ SCIENCES: ANALYSIS OF A CONTINUED TRAINING COURSE
}

\author{
Aline Locatelli (alinelocatelli@upf.br) \\ (Universidade de Passo Fundo - UPF) \\ Eva Rita Machado Ferreira Crestani (evarita.ferreira@hotmail.com) \\ (Universidade de Passo Fundo - UPF)
}

\section{Cleci Teresinha Werner da Rosa (cwerner@upf.br)}

(Universidade de Passo Fundo - UPF)

\begin{abstract}
Resumo: O presente trabalho relata uma investigação que teve por objetivo analisar que medida uma proposta de ensino interdisciplinar, ministrada em um curso de formação continuada de professores, contribui para sua estruturação e implementação no contexto escolar. Tal proposta de ensino, assim como a do curso ministrado, foi elaborada seguindo os Três Momentos Pedagógicos (3MP) e aplicada a professores de Química, Física e Biologia. O curso de formação teve a duração de dezesseis horas/aula e discutiu o entendimento de um ensino interdisciplinar e estruturado nos 3MP. Além disso, oportunizou a elaboração de uma atividade interdisciplinar envolvendo o tema "calor" para as disciplinas de Física, Química e Biologia da segunda série do ensino médio. A avaliação do estudo buscou, no relato das professoras participantes, analisar a pertinência do proposto no curso, estabelecendo quatro categorias de análise: "Compreensão sobre interdisciplinaridade", "Conhecimento sobre o uso de temas", "O conceito de calor e o trabalho pedagógico" e "Dificuldades e potencialidades na realização de um trabalho interdisciplinar". Os resultados apontaram que as atividades integradas podem resultar em aproximações entre os professores e, com isso, proporcionar mudança de postura e atitude não apenas nos relacionamentos interpessoais, mas também em relação ao fazer pedagógico.
\end{abstract}

Palavras-chave: Três Momentos Pedagógicos; Formação de professores; Interdisciplinaridade.

Abstract: The present work reports an investigation whose objective was to analyze to what extent an interdisciplinary teaching proposal, taught in a course of continuing teacher training, contributes to its structuring and implementation in the school context. This proposal of teaching, as well as that of the course taught, was elaborated following the Three Pedagogical Moments (3PM) and applied to professors of Chemistry, Physics 
and Biology. The training course lasted for sixteen hours/class and discussed the understanding of an interdisciplinary teaching and structured in the 3PM. In addition, he offered the opportunity to create an interdisciplinary activity involving the theme "heat" for the disciplines of Physics, Chemistry and Biology of the second series of High School. The evaluation of the study sought in the report of the participating teachers, to analyze the pertinence of the proposed course, establishing four categories of analysis: "Understanding about interdisciplinarity"; "Knowledge about the use of themes"; "The concept of heat and pedagogical work"; and "Difficulties and potentialities in the accomplishment of an interdisciplinary work". The results pointed out that integrated activities can result in approximations among teachers and thus provide a change of posture and attitudes, not only in interpersonal relationships, but also in relation to pedagogical doing.

Keywords: Three Pedagogical Moments; Teacher training.

\section{INTRODUÇÃO}

A legislação nacional exemplificada na voz dos Parâmetros Curriculares Nacionais (PCNs) (BRASIL, 1999) e na Base Nacional Curricular Comum (BNCC) (BRASIL, 2017), somada às pesquisas no campo da Educação, evidencia a necessidade e importância de um ensino interdisciplinar e contextualizado, que direcione as ações em sala de aula para a realidade dos alunos e para o que esperam apreender e conhecer quando chegam à escola. Para concretizar esse ensino, há necessidade de apresentar propostas didáticas que, além de estarem voltadas à interdisciplinaridade e contextualização, também despertem nos alunos o interesse e a curiosidade pela ciência e contribuam para a alfabetização científica. O objetivo está em ofertar aos estudantes oportunidades para refletir sobre as complexas relações entre ciência e sociedade, ampliando o seu olhar sobre o mundo em que vivem.

Apesar da existência de um número significativo de pesquisas que buscam avanços na área da Educação, em especial na Educação em Química, percebe-se que os conteúdos, em muitas escolas, continuam sendo abordados numa organização linear e de maneira fragmentada. Sobre isso Giacomini e Muenchen (2015, p. 341) mencionam que "tem-se a preocupação com a quantidade de conteúdos a serem ensinados e nem sempre com o porquê e com a qualidade do processo ensino/aprendizagem." Além disso, o ensino tem se mantido preso a materiais didáticos, livros, apostilas, com pouca atenção para a significação de conceitos que permitam estimular o pensamento crítico 
do aluno sobre o mundo. Situação particularmente favorecida dentro de uma abordagem didática interdisciplinar.

No ensino de Química, essa análise recai sobre a ênfase demasiada nos conteúdos, que são fragmentados e distantes das situações vivenciais dos alunos. O ensino, grande parte das vezes, é focado na decoreba de regras e fórmulas que pouco contribuem para o entendimento da Química como algo presente no entorno dos alunos.

Na defesa da necessidade de (re)estruturar o ensino de Química, focando na interdisciplinaridade, Abreu e Lopes (2010, p. 90) ressaltam que:

[...] a utilização da interdisciplinaridade como estratégia de ensino capaz de tornar o Ensino de Química mais significativo para o aluno engloba desde uma nova forma metodológica até uma concepção mais problematizadora, quando aparece associada à formação de valores e de atitudes críticos considerados essenciais para o indivíduo como cidadão.

Todavia, para que a interdisciplinaridade chegue ao cotidiano da escola, é necessário que os professores se sintam em condições de inseri-la em seu contexto de ensino. Para isso, uma possibilidade é criar espaços de diálogo para que os professores de diferentes áreas possam trocar experiências e elaborar ações conjuntas. Essa situação, que é pouco comum nas escolas, leva a reflexões sobre como contribuir na formação de professores interdisciplinares: como realizar um trabalho interdisciplinar na escola? Como proporcionar espaços de trocas entre os professores no contexto escolar? Tais questionamentos levam a formação inicial ou continuada dos professores como alternativa para que tenham oportunidade de ampliar seus conhecimentos específicos e pedagógicos, bem como identificar as relações do seu campo de atuação com a de seus colegas, especialmente em áreas próximas, como é o caso das disciplinas da área de Ciências.

Partindo da preocupação com a necessidade de efetivar um ensino de Química interdisciplinar e voltado a enfatizar aspectos da realidade dos alunos, apresentam-se, neste texto, os resultados de uma pesquisa que teve como objetivo analisar em que medida uma proposta de ensino que inter-relaciona as disciplinas da área de Ciências da Natureza, elaborada em um curso de formação de professores, contribui para um ensino interdisciplinar. 
Tal proposta de ensino foi elaborada em um curso de formação continuada de professores que contemplou aspectos teóricos e didáticos a partir dos 3 Momentos Pedagógicos (3MP), conforme Delizoicov e Angotti (1991). As percepções dos participantes forneceram elementos para responder ao questionamento central do estudo: quais as potencialidades e os desafios de realizar um trabalho pedagógico interdisciplinar?

Para responder a tal indagação, este texto estrutura-se do seguinte modo: nas próximas duas seções, são apresentadas reflexões sobre o entendimento de interdisciplinaridade e sobre os 3MP. Em seguida, apresenta-se o curso de formação, para, na sequência, descrever os aspectos metodológicos da pesquisa desenvolvida. Logo mais, expõem-se os resultados obtidos e encerra-se com as considerações finais.

\section{APORTES TEÓRICOS}

\section{Interdisciplinaridade}

A palavra "interdisciplinaridade" traz implícita inúmeras possibilidades de interpretações e compreensões, o que acaba repercutindo em diferentes conceptualizações. Para Fazenda (1996, p. 25), a interdisciplinaridade caracteriza-se "pela intensidade das trocas entre os especialistas e pelo grau de integração real das disciplinas no interior de um mesmo projeto de pesquisa." Continua a autora destacando que ela representa

[...] a passagem de uma subjetividade para uma intersubjetividade e, assim sendo, recupera a ideia primeira de Cultura [formação do homem total], o papel da escola [formação do homem inserido em sua realidade] e o papel do homem [agente das mudanças no mundo] (FAZENDA, 1996, p. 48).

Japíassu (1976, p. 75), por sua vez, assim define a interdisciplinaridade:

[...] podemos dizer que nos reconhecemos diante de um empreendimento interdisciplinar todas as vezes em que ele conseguir incorporar os resultados de várias especialidades, que tomar de empréstimo a outras disciplinas certos instrumentos e técnicas metodológicos, fazendo uso dos esquemas conceituais e das análises que se encontram nos diversos ramos do saber, a fim de fazê-los integrarem e convergirem, depois de terem sido comparados e julgados. Donde podermos dizer que o papel específico da atividade interdisciplinar consiste, primordialmente, em lançar uma ponte para ligar as fronteiras que haviam sido estabelecidas anteriormente entre as disciplinas 
com o objetivo preciso de assegurar a cada uma seu caráter propriamente positivo, segundo modos particulares e com resultados específicos.

Segue o autor mencionando que, ao se referir ao termo "interdisciplinar", deve-se reconhecer que não há um sentido epistemológico único e estável. Trata-se de um neologismo cuja significação nem sempre é a mesma e cujo papel nem sempre é compreendido da mesma forma.

Retomando novamente as ideias de Fazenda (2011, p. 13), percebe-se que "é impossível a construção de uma única, absoluta e geral teoria da interdisciplinaridade, mas é necessária a busca ou o desvelamento do percurso teórico pessoal de cada pesquisador que se aventurou a tratar as questões desse tema." Nesse sentido, vários significados são atribuídos para o termo interdisciplinaridade, que, segundo Lavaqui e Batista (2007), revelam uma variação do entendimento conceitual.

Independentemente da definição encontrada na literatura especializada, é importante ter a clareza de que a interdisciplinaridade está sempre voltada à preocupação com a superação da fragmentação da ciência e dos conhecimentos produzidos. Sobre essa variação de entendimentos, Japiassú (1976) ressalta que, embora haja variações, o termo mantém um núcleo coeso sobre o qual o sentido é sempre o mesmo, evidenciando que a interdisciplinaridade é caracterizada pela intensidade das trocas estabelecidas entre os sujeitos e pelo real grau de integração entre as disciplinas envolvidas em um projeto em comum.

Portanto, o mais importante não é atribuir um significado para a palavra interdisciplinaridade, mas buscar seu sentido epistemológico e a forma como ela pode ser trazida para o campo pedagógico. O importante é encontrar seu papel, suas implicações e as suas contribuições para o processo do conhecer e do ensinar. Em particular, para o ensino de Química, Abreu e Lopes (2010, p. 90) defendem que

[...] a utilização da interdisciplinaridade como estratégia de ensino capaz de tornar o ensino de Química mais significativo para o aluno engloba desde uma nova forma metodológica até uma concepção mais problematizadora, quando aparece associada à formação de valores e de atitudes críticos considerados essenciais para o indivíduo como cidadão.

O exposto leva à necessidade de se compreender que, para possibilitar a interdisciplinaridade, é preciso que o professor, ao abordar um tema ou conteúdo em 
sala de aula, estabeleça relações com outros campos do saber. Por exemplo, é necessário realizar a aproximação ou integração entre conceitos das outras ciências, a fim de buscar responder, conhecer e refletir aspectos da sua disciplina, bem como estabelecer relações com as questões sociais, científicas e tecnológicas. Para Freire (1987), a interdisciplinaridade transcorre no processo de construção do conhecimento do sujeito e suas relações com a realidade, a cultura, possibilitando ao sujeito a reflexão crítica que o leva a realizar a integração entre suas partes.

Nesse mesmo sentido, Abreu e Lopes (2010, p. 88) destacam que, para compreender como "determinada questão afeta o indivíduo na sociedade, é preciso conhecer e inter-relacionar os diferentes conhecimentos envolvidos, pois eles não funcionam isoladamente ou disciplinarmente." Isso justifica a necessidade de haver maior diálogo entre as ciências, entre as disciplinas escolares, representando uma possibilidade de discutir temas que inter-relacionem diferentes campos do saber.

Outro aspecto importante para um trabalho interdisciplinar consiste no uso da palavra, no diálogo e no conhecer o outro. Fazenda (2011, p. 55) observa isso ao afirmar que

[...] o homem vai atingindo o conhecimento de si na medida em que se revela. Esse conhecimento de si cresce na medida em que o homem procura conhecer o outro e esse conhecimento do outro só ocorre quando existe uma perfeita identificação entre o eu e o outro, ou seja, o homem só se realiza, só se conhece no "encontro" com o outro.

Nessa perspectiva, ressalta-se a importância da interação com o outro, do diálogo com os alunos em sala de aula e com os professores da escola. Um trabalho interdisciplinar não pode ser solitário, ele implica interações com o outro para além de um diálogo do leitor com o autor. Para Japiassú (1976, p. 26), “a exigência interdisciplinar impõe a cada especialista que transcenda sua própria especialidade, tomando consciência de seus próprios limites para acolher as contribuições das outras disciplinas." Nesse contexto, a interdisciplinaridade requer um diálogo entre sujeitos e entre saberes, levando a necessidade de buscar propostas didáticas que oportunizem essa abordagem, como é o caso dos 3MP.

\section{Os Três Momentos Pedagógicos (3MP)}


Acredita-se que um caminho para o trabalho interdisciplinar na escola possa estar na utilização de metodologias que envolvem a problematização como aspecto norteador das discussões em sala de aula. Essa problematização pode estar relacionada à busca por situações vivenciais e próximas dos alunos, envolvendo aspectos sociais e culturais de seu entorno. Nesse viés, estão propostas didáticas e de organização curricular como a desenvolvida por Delizoicov e Angotti (1991), denominada de "Três Momentos Pedagógicos".

A abordagem dos 3MP tem como aspectos principais: a conexão entre os conteúdos e os temas, a superação dos principais problemas do ambiente escolar, a problematizações dos temas a serem abordados, estimular o aluno a refletir de acordo com sua realidade e com isso proporcionar que ele seja protagonista no processo de ensino e de aprendizagem. (GIACOMINI, MUENCHEN, 2015).

Sobre a utilização dos 3 MP, Araújo (2015, p. 105) menciona que:

[...] a partir da utilização dos 3MP como estruturantes de currículos, bem como ferramenta metodológica, educador e educandos encontram-se numa relação horizontal de diálogo e saberes, sendo que o conhecimento apresentado por ambos é fundamental no processo de ensino-aprendizagem.

Nesse contexto, essa abordagem curricular ou metodológica de ensino, que recorre à perspectiva dialógico-problematizadora de Freire (1987), é estruturada em três momentos específicos e diferenciados, os quais são denominados de "Momentos Pedagógicos", assim identificados: Problematização Inicial (PI), Organização do Conhecimento (OC); Aplicação do Conhecimento (AC).

A PI representa o momento em que o professor parte de alguma situação que contemple a realidade dos alunos, normalmente trazida por eles para a sala de aula. Esse é o momento em que devem ser desafiados a compartilhar o que pensam e/ou sabem sobre o assunto. $\mathrm{O}$ professor, nesse momento, tem o papel de mediar a discussão e coordenar, levantando questionamentos, dúvidas sobre o assunto, fortalecendo a discussão, tendo um papel de questionador e não de portador de respostas. O objetivo desse momento é que o aluno tenha uma visão geral e crítica sobre o assunto.

O segundo momento representado pela OC enfatiza os conhecimentos científicos selecionados para aprofundamento a partir do tema discutido na PI. É nesse momento 
que os conhecimentos científicos são discutidos, recorrendo a materiais didáticos e atividades que permitam instigar no aluno a vontade de aprender, de buscar solução ao problema apresentado.

$\mathrm{O}$ último momento corresponde à $\mathrm{AC}$, na qual é realizada a sistematização do conhecimento. $\mathrm{O}$ aluno deve ser capaz de empregar o conhecimento que aprendeu em situações reais, situações da sua vivência, a fim de resolver problemas e determinadas atividades, articulando, assim, os conhecimentos científicos com situações reais.

\section{O CURSO DE FORMAÇÃO ESTRUTURADO NOS 3MP}

Para a operacionalização de uma proposta interdisciplinar, foi estruturado um curso de formação continuada de professores que contemplou aspectos teóricos e didáticos envolvendo os 3 Momentos Pedagógicos (3MP), como descrito na introdução deste texto. Os participantes dessa atividade foram três professoras de uma escola estadual no norte do Rio Grande do Sul, sendo uma de Química (PQ), uma de Física (PF) e outra de Biologia (PB). A PQ é uma das autoras deste trabalho e pesquisadora ministrante das atividades. Todas as professoras apresentam graduação nas áreas/disciplinas em que atuam e têm mais de cinco anos de experiência profissional no ensino médio.

$\mathrm{O}$ curso foi organizado dentro da metodologia dos 3MP como forma de que as professoras vivenciassem na prática a organização dessa dinâmica, que futuramente subsidiaria as ações didáticas. As atividades desenvolvidas no curso foram organizadas pelas autoras do trabalho e operacionalizadas em oito encontros, cada um com duas horas/aula, totalizando dezesseis horas de atividades.

Inicialmente, a proposta didática e a forma de organização das atividades relacionadas ao curso de formação foram apresentadas às participantes. Ainda nesse momento, foi realizada uma entrevista semiestruturada com objetivo de conhecer as docentes e saber qual a compreensão e o conhecimento que apresentavam sobre interdisciplinaridade, 3MP e, ainda, se já haviam trabalhado com propostas interdisciplinares e com o uso de problematização no ensino. 
Como PI, tomou-se a identificação de que as professoras participantes, embora soubessem do que tratava a interdisciplinaridade, não haviam trabalhado com propostas didáticas nessa abordagem. A partir dessa identificação, passou-se a discutir o tema e sua contemplação no contexto da sala de aula, identificando-o como um problema que elas gostariam de abordar nos encontros. Dessa forma, o tema selecionado como situação problematizadora do estudo foi a forma como poderia ser organizada uma sequência didática (SD) interdisciplinar envolvendo uma situação de interesse dos participantes. Como indicado no entendimento de PI, a situação-problema deve ser definida a partir dos interesses dos envolvidos, de modo a possibilitar que, ao final e de posse dos conhecimentos necessário, possam ser inferidas alternativas para solução.

Para iniciar as discussões relativas aos conhecimentos que poderiam subsidiar respostas ao problema apresentado, foi lido com os participantes um texto referente aos 3MP, uma vez que essa seria a estrutura do curso. Para tanto, o texto selecionado foi "Os três momentos pedagógicos e o contexto de produção do livro "Física" (MUENCHEN; DELIZOICOV, 2014). No encontro seguinte e dando continuidade às discussões teóricas relativas aos conhecimentos, foi abordado o tema "interdisciplinaridade". Como referencial de discussões, foi utilizado o texto "Interdisciplinaridade no ensino de Ciências: possibilidades e desafios para a formação de professores." (VENTURI; CLEBSCH; LUCA, 2016). A escolha desse texto teve como critério o fato de apresentar reflexões acerca de uma experiência didática, envolvendo a interdisciplinaridade e os $3 \mathrm{MP}$ - o que é de particular interesse para o estudo em desenvolvimento. Além dos referenciais mencionados em cada um dos encontros, foram indicadas outras obras e artigos que tratam das respectivas temáticas.

O terceiro encontro foi marcado pelo desafio de elaborar uma SD utilizando os 3MP e inter-relacionando os conteúdos de Química, Física e Biologia. Para a elaboração da sequência, os participantes realizaram um estudo prévio sobre os conteúdos abordados em suas respectivas disciplinas em cada uma das séries, identificando a possibilidade de abordar o tema "energia", mais especificamente o estudo do calor. A partir dessa identificação, passaram a discutir possibilidades de como poderiam contemplar esse conceito de maneira interdisciplinar. A opção do tema "calor" foi associada ao corpo humano, de modo que os conteúdos programáticos de cada uma das 
disciplinas envolvidas pudessem se estruturar em torno das discussões desse conceito. Cabe destacar que a turma escolhida foi a da $2^{\text {a }}$ série do ensino médio e os tópicos identificados como potencialidades para a discussão foram Termoquímica (Química), Termologia e Termodinâmica (Física), Fisiologia Humana (Biologia). Tais conteúdos estavam presentes no plano anual elaborado pela escola para a série selecionada, facilitando o pensar na inter-relação entre essas disciplinas do conhecimento.

Como forma de estruturar os conceitos selecionados para o estudo do tema, no quarto encontro, organizou-se um mapa mental. De acordo com Broietti et al. (2013, p. 1044), “os mapas mentais são utilizados nas mais variadas aplicações profissionais sendo considerados uma estratégia de organização de pensamentos.” A Figura 1elucida o Mapa Mental produzido pelas professoras usando o software https://coggle.it/.

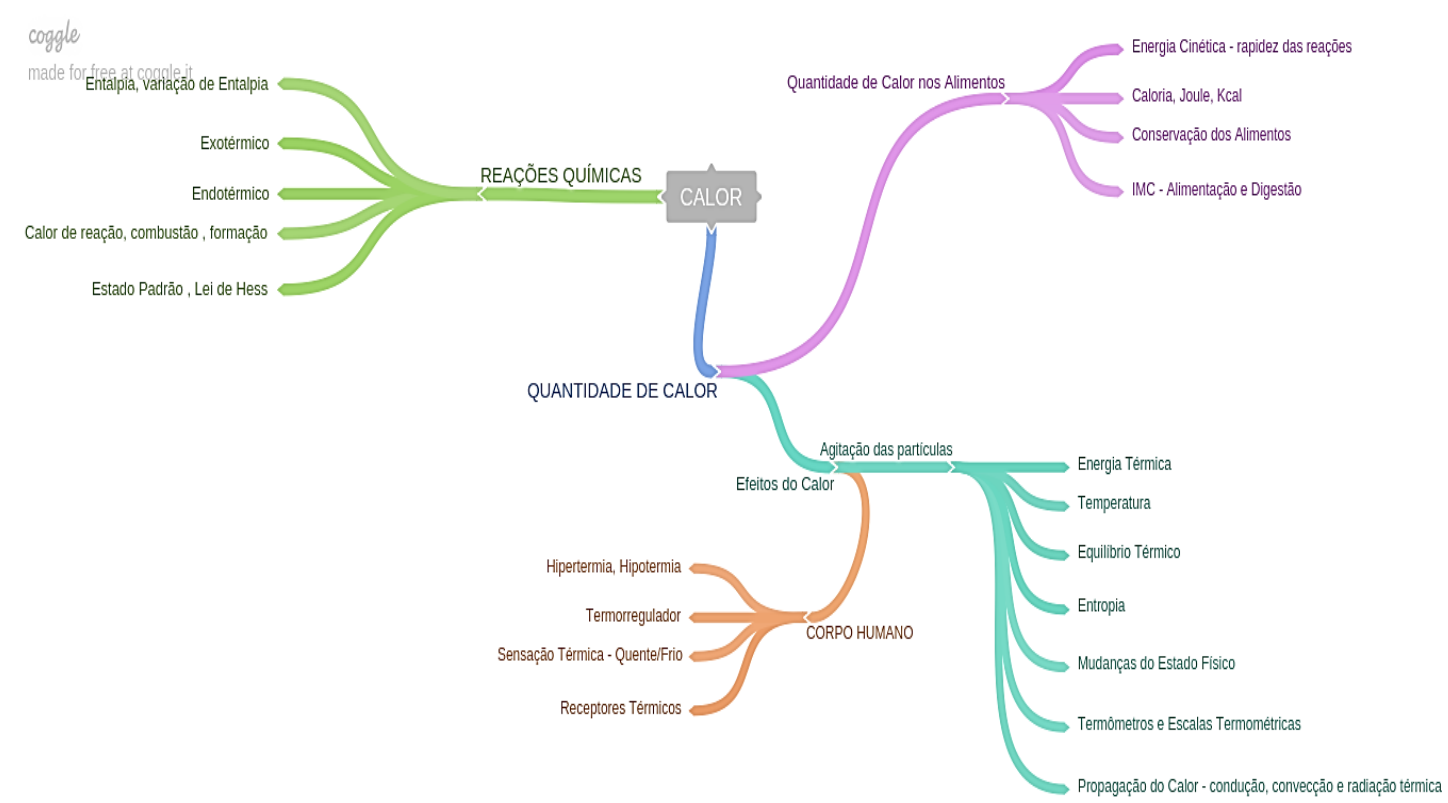

Figura 1 - Mapa mental produzido pelas professoras. Fonte: dados de pesquisa (2018).

O objetivo desse mapa foi visualizar a forma como os conteúdos de cada disciplina poderiam ser integrados e quais os aspectos comuns entre elas.

No quinto e sexto encontro, as professoras trabalharam na elaboração da SD, tomando como aspecto inicial a identificação de uma possibilidade de PI a ser 
estabelecida com os alunos no momento da operacionalização dessa SD. Nesse sentido, identificaram como possibilidade o seguinte questionamento: como os alimentos são transformados em energia para o nosso corpo?

A partir desse questionamento e nos encontros seguintes foram estruturadas as atividades e conteúdos que poderiam ser contemplados na operacionalização da SD interdisciplinar e a forma como as professoras organizariam as atividades dentro da carga horária prevista para cada uma das disciplinas envolvidas.

Como última atividade do curso, organizou-se um momento de apresentação das $\mathrm{SD}$, o que envolveu muita discussão sobre sua viabilidade e potencialidade, retomando a situação-problema apresentada no primeiro encontro. Para encerrar as atividades do curso de formação continuada, foi realizada uma entrevista com as participantes e que será discutida na sequência.

\section{A PESQUISA}

Durante o desenvolvimento da proposta didática mencionada na seção anterior, foi realizada uma investigação buscando responder ao questionamento central desse estudo. Para tanto, tomou-se como referencial teórico-metodológico o entendimento de uma pesquisa de caráter qualitativo, associada a uma intervenção-ação. A abordagem qualitativa decorre do entendimento de que a realidade estudada não será analisada a partir de dados quantitativos, pois o foco está em compreender e explicar a dinâmica das relações sociais estabelecidas durante o estudo, conforme mencionado por Minayo (2007).

O objetivo da pesquisa foi analisar quais as potencialidades e os desafios em elaborar uma SD que inter-relacionou as disciplinas da área de Ciências da Natureza em um curso de formação de professores. Para isso, utilizaram-se como instrumentos de coleta de dados as entrevistas semiestruturadas (etapa inicial e final do curso) apresentadas no quadro 1. A escolha da entrevista semiestruturada decorre do objetivo de permitir que os sujeitos se sentissem livres para expor e dialogar sobre o curso em investigação. De acordo com Gil (1987, p. 113), essas entrevistas podem ser consideradas uma forma de interação social, uma vez que elas consistem em um 
investigador frente a frente com seu investigado. Este trabalho foi aprovado pelo comitê de ética em pesquisa com seres humanos. Número do Comprovante: 076125/2017.

\section{Entrevista semiestruturada}

Etapa inicial - conhecimento sobre o tema e referências da pesquisa:

01 - O que você compreende sobre a Interdisciplinaridade?

02 - Qual é a sua opinião sobre o Ensino a partir de "temas"?

03 - Você conhece a dinâmica dos Três Momentos Pedagógicos? Qual é a sua opinião sobre essa proposta?

04 - Em que momento do seu trabalho (em quais conteúdos) você aborda o tema "CALOR"?

05 - Como você desenvolve esse tema?

06 - Que tipos de atividades e quais recursos pedagógicos você utiliza no desenvolvimento dos conhecimentos em sala de aula?

07 - No desenvolvimento do tema "CALOR" com seus alunos, que aspectos além dos conhecimentos da sua disciplina você trabalha com eles?

08 - Quais atividades podem ser realizadas com seus alunos, para que eles percebam a importância do estudo e compreensão do "Calor"?

09 - Escreva sobre alguma experiência referente ao uso de "temas" já desenvolvida com seus alunos.

10 - Você participa de algum projeto no qual interagem professores de diferentes disciplinas (áreas do conhecimento)? Em caso afirmativo. Fale um pouco do projeto.

11 - A Base Nacional para o Ensino Médio recomenda que o ensino seja trabalhado de forma contextualizada e interdisciplinar. Em sua opinião é possível trabalhar dessa forma em todos os conhecimentos de Ciências da Natureza do Ensino Médio? Ou apenas em alguns temas específicos? Para você, quais temas são mais propícios e por quê?

12 - Na sua opinião quais as principais dificuldades encontradas em realizar um trabalho interdisciplinar na escola?

\section{Etapa final - conhecimento sobre o tema e referências da pesquisa:}

01 - O que você compreendeu sobre a Interdisciplinaridade participando dessa pesquisa?

02 - Como foi trabalhar na sala de aula a partir de um "tema", o Calor?

03 - Quais os pontos positivos em trabalhar com a metodologia dos Três Momentos Pedagógicos?

04 - Quais foram às dificuldades em trabalhar com essa metodologia?

05 - Existem diferenças entre as aulas desenvolvidas a partir da dinâmica dos 3MP das aulas que você planejava antes do projeto? Quais?

06 - Como foi participar e desenvolver um projeto interdisciplinar na escola, aspectos positivos e dificuldades encontradas?

07 - No desenvolvimento do tema "CALOR" com seus alunos, que aspectos além dos conhecimentos da sua disciplina foram possíveis trabalhar com eles?

08 - Como você avalia a aprendizagem dos alunos no desenvolvimento das aulas do projeto? Foi possível perceber o desenvolvimento de alguma competência (pesquisa, autonomia...)?

09- Faça uma avaliação do trabalho desenvolvido, suas expectativas foram alcançadas? O que poderia ser melhorado ou redimensionado?

Quadro 1 - Entrevistas semiestruturadas. Fonte: dados de pesquisa (2018). 
A metodologia de análise da pesquisa foi a Análise de Conteúdo proposta por Bardin (2009), essa se constitui em um conjunto de procedimentos de análise das comunicações que utiliza métodos sistemáticos e objetivos de descrição do conteúdo das mensagens. A modalidade da Análise de Conteúdo será a análise temática, que conforme Minayo (2007, p. 316) ocorre em três fases: Pré-análise, em que se organiza o que vai ser analisado; Exploração do material: momento de codificação do material de onde surgem as categorias; e Tratamento dos resultados: interpretação dos dados e destaque das informações obtidas.

\section{RESULTADOS E DISCUSSÃO}

Os resultados foram divididos em quatro categorias de análise, definidas pela intencionalidade da pesquisa realizada e a partir dos instrumentos de coleta de dados (entrevistas inicial e final). Tais categorias definidas a posteriori emergiram da leitura dos materiais produzidos na investigação e foram assim identificadas: "Compreensão sobre interdisciplinaridade", "Conhecimento sobre o uso de temas", "O Conceito de calor e o trabalho pedagógico", "Dificuldades e potencialidades na realização de um trabalho interdisciplinar". A análise que segue toma tais categorias como referencial, trazendo à discussão aspectos decorrentes das falas das participantes. Essas falas foram transcritas na integra, destacadas no texto em itálico, corrigindo os vícios de linguagem. A identificação dos participantes é dada pela utilização de PF para professora de Física e PB para a de Biologia, seguindo o já utilizado neste texto.

\section{a) Compreensão sobre interdisciplinaridade}

Essa primeira categoria surgiu a partir da visão das professoras entrevistadas sobre o entendimento da interdisciplinaridade. Ambas apresentam inicialmente um entendimento sobre o tema que vem ao acordo dos autores que são referências no assunto e foram mencionados anteriormente. Pode-se perceber que ambas possuem a ideia de integração entre as áreas do conhecimento, conforme pode ser analisado nas palavras das professoras: "Esse termo estabelece relações entre duas ou mais disciplinas, ou o que é comum a duas ou mais disciplinas" (PF); "Interação das disciplinas em um tema central, troca e interação de conhecimentos" (PB). Na 
entrevista final, ao serem questionadas sobre o que aprenderam sobre o tema, PB mencionou a importância da atividade de leitura dos textos realizada no início do curso.

Sobre isso, a PF destacou na entrevista final: "A interdisciplinaridade é uma proposta que consta nos documentos oficiais. São ações que buscam assegurar o conhecimento sobre um tema em diferentes disciplinas, propiciam a troca de saberes nos diferentes campos do conhecimento. A interdisciplinaridade é possível e os resultados são muito bons". Nessa resposta, fica evidenciada uma característica da interdisciplinaridade defendida por Fazenda (2011), de que ela não é categoria de conhecimento, mas de ação. Nesse sentido, a interdisciplinaridade são as ações, propostas, metodologias que o professor utiliza no seu planejamento e prática com seus alunos, objetivando construir coletivamente conhecimentos mais elaborados e com a participação de diferentes disciplinas.

Quando questionadas sobre como foi participar de um curso que envolveu interdisciplinaridade na escola, aspectos positivos e dificuldades encontradas, as professoras apresentaram diferentes opiniões. A PF ressaltou: "Para mim, não foi difícil. Sou uma pessoa aberta e teria que preparar as aulas participando ou não do curso. Como aspectos positivos e que na minha opinião foi muito interessante porque o tema era abordado com frequência nas três disciplinas. E a interdisciplinaridade foi muito bom também". No entendimento da PB, tem-se que: "Foi incrível trabalhar, até comentamos se possível aperfeiçoar este conteúdo e até realizar projetos interdisciplinares em outros conceitos. A cada trabalho sempre é complicado e uma nova experiência".

As falas reafirmam a importância da interdisciplinaridade na integração das disciplinas. Retomamos as palavras de Japiassú (1976, p. 54):

\footnotetext{
A interdisciplinaridade se apresenta como uma oposição sistemática a um tipo tradicional de organização do saber. Bem como, uma reflexão epistemológica sobre a divisão do saber em disciplinas para extrair suas relações de interdependências e de conexões recíprocas. Portanto, numa primeira aproximação, a interdisciplinaridade se define e se elabora por uma crítica das fronteiras das disciplinas, de sua compartimentação, proporcionando uma grande esperança de renovação e de mudança.
}

Deve-se ter a clareza de que a interdisciplinaridade está sempre voltada à preocupação com a superação da fragmentação da ciência e dos conhecimentos 
produzidos. Assim, interdisciplinaridade não é romper com as disciplinas, mas respeitar as diversas áreas do conhecimento, integrando-as por meio do diálogo, da parceria, da reciprocidade, com uma visão de conhecimento mais amplo e abrangente.

A interdisciplinaridade apresenta-se como uma metodologia em que se respeita a especificidade de cada área, procurando estabelecer e compreender as relações entre os conhecimentos sistematizados, ampliando o espaço de diálogo na direção da negociação de ideia e da aceitação de outras visões (WEIGERT; VILLANI; FREITAS, 2005).

Portanto, o mais importante não é somente atribuir um significado para a palavra interdisciplinaridade, mas buscar o seu sentido epistemológico. Encontrar seu papel, suas implicações e contribuições para o processo do conhecer. Realizar uma revisão de pensamento, que caminhe para o diálogo, para a troca, para a integração conceitual e metodológica nos diferentes campos do saber.

\section{b) Conhecimento sobre o uso de temas}

A segunda categoria decorre do conhecimento mencionado pelas professoras com relação ao ensino a partir de "temas". Freire (1987, p. 118) defende que os temas sejam usados "como problemas a serem decifrados jamais como conteúdos a serem depositados." Para o autor, no processo de redução temática, cada professor apresenta à equipe interdisciplinar a redução do seu tema. Cada professor busca relações com a sua especialidade estabelecendo conexões com as outras áreas, para que, ao final, tenha-se uma visão geral do tema reduzido. Segundo Japiassú (1976, p. 59):

A grande dificuldade consiste em encontrar um método que seja adequado e interdisciplinar. Sabemos que o primeiro elemento de um método consiste em corte da realidade, o que acarreta certa "redução" dessa realidade ou a formação de um esquema ideal mais ou menos simplificado. $\mathrm{O}$ segundo elemento consiste em procedimentos de investigação adaptados à realidade assim "reduzida". O terceiro, em procedimentos de representação capazes de exprimir de modo mais ou menos preciso as investigações e resultados. Finalmente, o método comporta procedimentos de explicação, isto é, uma linguagem teoria capaz de reencontrar dedutivamente os dados empíricos e, assim, "explicá-los".

Nesse sentido, é necessário compreender que, para possibilitar a interdisciplinaridade no ensino de Ciências da Natureza, ou em qualquer outra área de ensino, é preciso saber que, ao abordar um tema/assunto numa aula, é necessário estabelecer relações com outros campos do saber. Realizar essas diferentes relações 
conceituais é uma atividade complexa e exige que o professor saiba uma gama cada vez mais ampla de conhecimentos. Também, que consiga trabalhá-los de maneira mais integrada e relacionada, permitindo aos estudantes espaços para realizarem essas conexões.

$\mathrm{Na}$ visão das professoras, o uso de temas, se for bem organizado, pode proporcionar bons resultados em sala de aula. Trabalhar a partir de temas é instigante tanto para os professores quanto para os alunos. A PB descreveu como se sente ao pensar em trabalhar com temas: "Desafiadora, motivante e muita expectativa, maravilhosa e em busca de ótimos resultados para a turma que será desenvolvida". A $\mathrm{PF}$ enfatizou ter conhecimento sobre o uso de temas por meio dos 3MP: "É uma dinâmica onde o primeiro momento se faz uma problematização inicial, o segundo momento é a organização do conhecimento, e o terceiro é a aplicação do conhecimento". A professora teve conhecimento dos 3MP em um curso de formação continuada que realiza.

Quando desafiadas a escrever sobre alguma experiência já desenvolvida sobre o uso de temas, a PF descreveu: "Seminário do Meio Ambiente - distribuição de mudas arbóreas, em pontos específicos, para a população." Já a PB afirmou: "A escola trabalha com tema gerador ${ }^{l}$, mas tentamos interligar conceitos, atitudes, mas é difícil".

A escola, lócus da presente prática, todo ano faz uma investigação sobre o tema a ser trabalhado no próximo ano letivo. Cada área do conhecimento tem o desafio de realizar atividades utilizando o tema geral da escola. A área das Ciências da Natureza, nesse ano letivo (2018), organizou um pedágio do meio ambiente, com o objetivo de conscientizar a população com relação à preservação do meio ambiente, fazendo a doação de mudas e incentivando o plantio de árvores nativas. O tema da escola é "Sucesso escolar: educação e atitude em defesa da vida."

Quanto à dificuldade enfrentada pela PB, destaca-se que é um relato a partir do problema que os professores da área têm para organizar as atividades a serem desenvolvidas durante o ano letivo. Apesar de darem exemplos sobre o trabalho com o 1 nomenclatura utilizada pela escola. Salienta-se que o presente estudo não teve como objetivos
aprofundar se é gerador ou não. 
uso de temas, quando questionadas se participam de algum projeto no qual interagem professores de diferentes disciplinas, as duas professoras responderam que não participam. Afirmaram que a presente pesquisa seria o primeiro projeto a ser desenvolvido.

Percebe-se que a resposta das professoras está relacionada ao fato de que, apesar de a escola ter um tema gerador e algumas atividades serem planejadas pelas áreas do conhecimento, o dia a dia na sala de aula não é planejado em conjunto, por meio da troca de ideias com outros professores. Cada professor organiza as suas aulas de acordo com o tema da escola, mas pouco se sabe realmente sobre quais conteúdos e conceitos cada professor trabalha, nem como trabalha em sua disciplina. Isso nos mostra que, apesar de a escola trabalhar com temas, ainda há dificuldade do diálogo, da integração e da parceria num planejamento coletivo e interdisciplinar entre os colegas professores.

Ressalta-se que a proposta do uso de temas também se apresenta nos PCNs (BRASIL, 1999). No referido documento a sugestão é trabalhar com temas transversais, os quais estejam direcionados à realidade que os estudantes estão inseridos, transformando dessa forma a organização tradicional das aulas e estimulando os professores a abordarem situações da vivência dos alunos, contribuindo com um trabalho interdisciplinar no ambiente escolar, que possa abarcar outras áreas do conhecimento bem como a comunidade local. (CRESTANI, LOCATELLI, GOMES, 2017).

A hipótese é de que, ao se trabalhar com temas que estejam de acordo com a realidade dos alunos, o interesse pelas aulas seja estimulado, pois estes terão a oportunidade de participar ativamente do processo, questionar mais e se sentirem responsáveis pela realidade que os cerca. Assim, essas ações podem contribuir não só com a aprendizagem do conhecimento escolar, mas também com a aprendizagem da cidadania, sociedade, cultura, tecnologia, ou seja, uma aprendizagem interdisciplinar. (CRESTANI, LOCATELLI, GOMES, 2017).

\section{c) $\mathrm{O}$ conceito de calor e o trabalho pedagógico}


A terceira categoria emergiu dos questionamentos realizados com as professoras a respeito de como ensinam o conceito de Calor, de que forma abordam esse conteúdo em sala de aula. Também foram questionadas sobre quais aspectos, além dos conhecimentos da sua disciplina, podem ser abordados com os alunos.

Percebeu-se, nas respostas das professoras, que ambas possuem conhecimento de como esse conceito está relacionado com diversos conteúdos da sua disciplina e não especificamente em um único conteúdo. Um exemplo está na fala da PF ao responder sobre em qual momento aborda o tema Calor: "Temperatura (equilíbrio térmico, medida de temperatura, conversão e escalas), dilatação linear, superficial $e$ volumétrica e dilatação de líquidos." O mesmo questionamento foi realizado para a $\mathrm{PB}$, obtendo-se como resposta: "Nos sistemas do Corpo Humano, seres vivos em geral, identificando a influência, informações e estímulos, Ciclos Biogeoquímicos, composição do alimento, energia, desde o nascimento até a decomposição dos seres vivos".

Quando questionadas acerca dos tipos de atividades e recursos pedagógicos que utilizam para o desenvolvimento das aulas, percebe-se que o ensino ainda apresenta resquícios de uma abordagem tradicional, com aulas expositivas, focada no livro texto e voltadas à resolução de problemas clássicos como os apresentados nos materiais didáticos. Além disso, elas mencionam o uso esporádico de atividades experimentais e vídeos, dependendo do tema em estudo. Nas falas, não foram identificadas situações didáticas que levem o aluno a ser desafiado a resolver problemas abertos, como os apresentados na metodologia dos 3MP. Além disso, não foi abordada pelas professoras uma preocupação em relacionar os conteúdos com o cotidiano dos alunos, instigando-o a pensar e refletir.

Em relação ao trabalho sobre o conceito de Calor, questionou-se sobre como poderiam contemplar aspectos para além da disciplina ministrada. Sobre isso, a PF respondeu: "Aspectos da vida diária”; e a da PB destacou: "Influência do calor nos nossos dias, aquecimento, sentidos e doenças." Em nenhum momento, foi trazida pelas participantes a questão de contemplar projetos educacionais na comunidade escolar, envolvendo situações trazidas pelos alunos. Os exemplos mencionados pelas duas professoras restringem-se a citar conteúdos em que o conceito possa ser trabalhado ou 
alguma atividade prática. Não relacionam a possibilidade para desenvolver projetos com outras disciplinas. Percebemos a dificuldade de pensar em um planejamento que possa ser desenvolvido no coletivo e que esteja além da sala de aula.

Ao final da atividade, quando foi retomado o questionamento sobre a escolha do tema "calor", as professoras responderam: "Foi muito bom. O calor é um tema que faz. parte das ações da vida diária dos alunos. Muitas atividades e ações exercidas envolvem esse tema. Foi relativamente fácil, os alunos já trazem de casa um conhecimento empírico" (PF). "Foi excelente, produtivo e maravilhoso. Mas complicado pela falta de prática e conhecimento, pois estamos habituados a realizar os métodos tradicionais" (PB). Nessas falas, é possível identificar que o uso dos temas facilita o trabalho do professor e a aprendizagem dos alunos, pois estes trazem conhecimentos prévios das ações realizadas no dia a dia, exatamente o que é defendido por Delizoicov, Angotti e Pernambuco (2007), de que a abordagem temática rompe com o currículo tradicional e contribui para um ensino com base numa abordagem conceitual.

\section{d) Dificuldades e potencialidades na realização de um trabalho interdisciplinar}

A análise das respostas das professoras sobre a realização de um trabalho interdisciplinar emergiu essa quarta categoria de análise, que diz respeito às dificuldades e às potencialidades da realização de um trabalho interdisciplinar.

Quando questionadas sobre ser possível trabalhar de forma interdisciplinar em todos os conteúdos de Ciências da Natureza do Ensino Médio, as duas professoras responderam positivamente, como evidenciado na fala da PF: “A Base Nacional Comum e a parte diversificada devem se comunicar com as disciplinas específicas para trabalharem cada uma das partes, de forma planejada e organizada. Penso ser possível trabalhar todos os conteúdos de ciências da natureza". Para a PB, tem-se que: "Sim, mas requer muito trabalho, dedicação, tempo disponível”. Essa professora citou alguns conteúdos que poderiam ser trabalhados dentro dessa abordagem, como "Sistemas, ecologia, seres vivos, animais e plantas" (PB). 
Com o aceno positivo para a possibilidade de trabalhar de maneira interdisciplinar em todos os conteúdos, questionou-se sobre as dificuldades para realizar esse trabalho interdisciplinar, uma vez que, se é possível trabalhar dessa forma, por que não o fazemos? Para a $\mathrm{PB}$, “A disponibilidade de tempo é a grande dificuldade destacada, pois os envolvidos precisam disponibilizar de mais tempo, pesquisa, organização e encontros para discutir; dessa forma, dificulta a realização”. Para a PF, a "Falta de tempo para o planejamento e o hábito de planejar com os demais colegas" representam a dificuldade para implementar projetos interdisciplinares na escola.

De fato, quem acompanha o dia a dia na escola sabe que, muitas vezes, os horários disponibilizados para o planejamento coletivo se restringem a cumprir algumas atividades burocráticas, como preenchimento de cadernos de chamada, pareceres de alunos, conversas com os pais, orientação, organização e escolha de livros didáticos, organização do laboratório de Ciências, datas festivas na escola e outros. Restando pouco tempo para o planejamento coletivo e o pensar sobre o que cada poderia realizar na sua disciplina e no coletivo da turma. Entretanto, Luca e colaboradores (2018) destacam a importância do planejamento para que o professor possa atuar como mediador permitindo discussões de situações significativas para além dos conteúdos.

Para trabalhar interdisciplinarmente, o professor também precisa pesquisar e ir em busca de novos conhecimentos, novas metodologias. Na fala da PF, por sua vez, percebe-se outra dificuldade: "o hábito" de planejar com os demais colegas. Muitos professores não foram formados para pensar, planejar e ensinar de maneira interdisciplinar. A professora ressalta: "Temos uma grande dificuldade em planejar no coletivo, em trocar ideias com outros colegas, em pensar não somente na nossa disciplina, mas pensar com um olhar mais abrangente" (PF). As dificuldades mencionadas pelas professoras são contempladas na fala de Fazenda (2011, p. 94):

Numa mesma instituição temos professores com diferentes práticas. Se a instituição propicia espaço, tempo e incentivo ao diálogo, é possível ao professor aprender com seus colegas. Muitas vezes, a solução de um problema, que para ele é difícil ou até mesmo insolúvel, torna-se simples, quando se estabelece a troca com o outro.

O trabalho interdisciplinar implica um trabalho coletivo. O professor precisa romper esse trabalho solitário, fechado entre as paredes da sala de aula, entre os muros 
da escola e aventurar-se num trabalho coletivo e interdisciplinar, sempre visando a um ensino de melhor qualidade e mais aproximado da realidade dos alunos. Um trabalho interdisciplinar requer um professor que esteja comprometido com o seu trabalho reafirmando esse compromisso diariamente na escola.

Em relação a possíveis dificuldades em trabalhar com a dinâmica dos $3 \mathrm{MP}$, as professoras relataram não terem encontrado grandes dificuldades. Na fala da PF, tem-se que: "Eu não tive dificuldades, muito pelo contrário me pareceu mais fácil”, para a PB, “Organização, seguir os cronogramas e a elaboração dos conceitos, práticas para cada conceito, tudo isso requer tempo para planejar e tempo para aplicação."

O exposto apontou que as professoras não apresentaram dificuldades com relação à estruturação das aulas seguindo os 3MP; todavia, relataram haver dificuldades em relação ao tempo de planejamento e execução das aulas. Quando questionadas se havia diferenças entre as aulas desenvolvidas a partir da dinâmica dos 3MP das aulas que planejavam antes do projeto, as professoras responderam: "Sim, pois planejamos as aulas separadamente sem a interação dos conceitos, apenas seguimos o cronograma dos conteúdos e a sequência de cada instituição e só percebemos a importância quando participamos do projeto, pois de outra forma acabamos por fazer trabalho mecânico" (PB). "Sim, porque foram planejadas todas as aulas e foi preciso seguir o passo a passo. E também foi pensando o diagnóstico para verificar o conhecimento prévio dos alunos e que antes não era feito, ou de forma superficial" (PF). Na fala da PB, percebese que o planejamento era realizado separadamente, seguindo a listagem de conteúdos de cada escola, de maneira "mecânica", no sentido de expressar sem reflexões, sem interação com outros conhecimentos. Só se percebeu a importância de realizar trabalhos no coletivo quando participou do curso.

As professoras identificaram diferenças significativas em elaborar as aulas seguindo os 3MP, destacando a importância da interação entre os conhecimentos, bem como o problematizar os conhecimentos prévios que os alunos trazem para dentro da sala de aula.

\section{CONSIDERAÇÕES FINAIS}


O presente estudo buscou analisar quais as potencialidades e os desafios em elaborar uma SD que inter-relacionou as disciplinas da área de Ciências da Natureza em um curso de formação de professores e avaliar em que medida essa proposta contribuiu para um ensino de Ciências da Natureza interdisciplinar. Para isso, as professoras participantes da pesquisa desenvolveram uma SD interdisciplinar à luz dos 3MP.

Dos resultados obtidos, destaca-se a importância da participação da escola num projeto dessa natureza, uma vez que é preciso que a escola propicie engajamento e espaços de diálogo entre os professores. Tais características sintetizam que uma prática de ensino interdisciplinar consiste num diálogo permanente do professor consigo mesmo, com os colegas, com a comunidade escolar, dentro de trabalho coletivo, de parceria e de comprometimento da equipe diretiva da escola. Isso tudo para além da integração de conhecimentos, áreas, disciplinas e a abertura para novas possibilidades de pesquisas, na busca por um conhecimento e visões de mundo mais amplas. Para Japiassú (1976, p. 45), existem dois modos de se conceber e praticar as pesquisas interdisciplinares: "se, de um lado, devemos comparar e congregar os conhecimentos, do outro, é preciso não esquecer que o conhecimento e a ação, longe de se excluírem, se conjugam."

$\mathrm{O}$ uso de temas trabalhados de maneira interdisciplinar pode proporcionar essas relações de trocas de saber entre alunos, professores, escola e comunidade. Como resultado do trabalho coletivo, ocorrerá a melhoria da qualidade na educação, a resolução de problemas locais, a conscientização dos sujeitos sobre a realidade. Assim, uma prática interdisciplinar implica uma revisão, reflexão das ações praticadas constantemente; sua construção fundamenta-se na possibilidade de trocas intersubjetivas (FAZENDA, 2011). Portanto, um trabalho interdisciplinar, além de promover trocas entre os professores e estimular o autoconhecimento de cada um, deve contribuir para a ampliação das leituras a respeito do assunto.

Ficou evidente a participação e envolvimento das professoras na realização do curso, apontando para uma possível mudança de postura e atitudes delas, que iniciaram timidamente o trabalho e, ao longo do estudo e elaboração da SD, mostraram-se mais confiantes no planejamento de atividades diferenciadas. A insegurança no decorrer do trabalho foi sendo substituída pela motivação e coragem de ousar e realizar o trabalho 
proposto. Ao final do processo, essas dificuldades já não se sobressaíam da mesma maneira, e a motivação e a importância de se realizar novos projetos seguindo essas metodologias ficaram evidenciadas.

Por fim, a interdisciplinaridade contribuiu para a articulação e interdependência entre os conceitos, o que pode contribuir de maneira significativa para o entendimento e aprendizagem dos alunos. A problematização a partir de temas cooperou para uma proposta interdisciplinar beneficiando o processo de ensino e aprendizagem do conhecimento científico para além da sala de aula. O curso desenvolvido favoreceu maior autonomia das professoras participantes, envolvendo-as ativamente nesse processo.

\section{REFERÊNCIAS}

ABREU, R. G. de; LOPES, A. C. A Interdisciplinaridade e o Ensino de Química: uma leitura a partir das políticas de currículo. In: SANTOS, W. P.; MALDANER, Otavio. A. (Org.). Química em Foco. Ijuí: Ed. da Unijuí, 2010. p. 77-99. (Coleção Educação em Química).

ARAÚJO, L. B. de. Os três momentos pedagógicos como estruturantes de currículos. 2015. Dissertação (Mestrado em Educação em Ciências) - Universidade Federal de Santa Maria, Santa Maria, 2015.

BARDIN, L. Análise de Conteúdo. Lisboa, Portugal; Edições 70, LDA, 2009.

BRASIL. Ministério da Educação, Secretaria de Educação Média e Tecnológica. Parâmetros Curriculares Nacionais: Ensino Médio: Área Ciências da Natureza e suas Tecnologias. Brasília: MEC/Semtec, 1999. Disponível em: $<$ http://portal.mec.gov.br/seb/arquivos/pdf/CienciasdaNatureza.pdf>. Acesso em: 02 fev. 2020.

BRASIL. Ministério da Educação e Cultura. Base Nacional Comum Curricular - $3^{\mathbf{a}}$ versão. Brasília, DF: MEC, 2017.

BROIETTI, F. C. D. et al. A temática "cheiro" no Ensino de Química: mapas mentais como estratégia metodológica. In: CONGRESSO INTERNACIONAL SOBRE INVESTIGACIÓN EN DIDÁCTICA DE LÃS CIENCIAS., 9, 2013, Girona. Anais... 2013. p. 1043-1048.

CRESTANI, E. R. M. F.; LOCATELLI, A.; GOMES, V. F. O ensino de química no paisagismo dos três momentos pedagógicos: uma análise das produções 
científicas. Revista Brasileira de Ensino Superior, Passo Fundo, v. 3, n. 4, p. 113-135, dez. 2017.

DELIZOICOV, D.; ANGOTTI, J. A. Física: formação geral. São Paulo: Cortez, 1991. (Coleção Magistério).

DELIZOICOV, D.; ANGOTTI, J. A. P.; PERNAMBUCO, M. M. C. A. Ensino de Ciências: fundamentos e métodos. 2. ed. São Paulo: Cortez, 2007.

FAZENDA, I. C. Integração e Interdisciplinaridade no ensino brasileiro. 4. ed. São Paulo: Loyola, 1996.

FAZENDA, I. C. Interdisciplinaridade: história, teoria e pesquisa. 18. ed. Campinas: Papirus, 2011.

FREIRE, P. Pedagogia do Oprimido. 17. ed. Rio de Janeiro: Paz e Terra, 1987.

GIACOMINI, A.; MUENCHEN, C. Os três momentos pedagógicos como organizadores de um processo formativo: algumas reflexões. Revista Brasileira de Pesquisa em Educação em Ciências, v. 15, n. 2, p. 339-355, 2015.

GIL, A. C. Como elaborar projetos de pesquisa. São Paulo: Atlas, 1987.

JAPIASSÚ, H. Interdisciplinaridade e patologia do saber. Rio de Janeiro: Imago, 1976. $221 \mathrm{p}$.

LAVAQUI, V.; BATISTA, I. L. Interdisciplinaridade em ensino de ciências e de matemática no ensino médio. Ciência \& Educação, v. 13, n. 3, p. 399-420, 2007.

MUENCHEN, C.; DELIZOICOV, D. Os três momentos pedagógicos e o contexto de produção do livro "Física". Ciência \& Educação, v. 20, n. 3, p. 617-638, 2014.

LUCA, A. G. de.; SANTOS, S. A. dos.; DEL PINO, J. C.; PIZZATO, M. C.

Experimentação contextualizada e interdisciplinar: uma proposta para o ensino de ciências. Revista Insignare Scientia, v. 1, n. 2, 2018.

MINAYO, M. C. de S. O desafio do conhecimento. 10. ed. São Paulo: Hucitec, 2007.

VENTURI, T.; CLEBSCH, A. B.; LUCA, A. G. de. Interdisciplinaridade no Ensino de Ciências: possibilidades e desafios para a formação de professores. Revista da SBEnBIO, n. 9, p. 305-318, 2016.

WEIGERT, C.; VILLANI, A.; FREITAS, D. A interdisciplinaridade e o trabalho coletivo: análise de um planejamento interdisciplinar. Ciência \& Educação, v. 11, n. 1, p. 145-164, 2005. 